\title{
Inflammation: An Equal-Opportunity Process
}

\author{
David B. Sachar
}

Published online: 25 January 2011

(C) Springer Science+Business Media, LLC 2011

Today's media are saturated with alarms about the dangers of obesity. We are warned about the impending epidemic of diabetes, heart disease, cancer, stroke, and a litany of other ailments. But who would have ever imagined that Crohn's disease would land on this list of horrors?

In this issue of Digestive Diseases and Sciences, investigators from St. George's Medical School in London suggest that obesity may play a role in the pathogenesis of Crohn's disease (CD) [1]. They arrived at this conclusion via observations on a series of 524 patients with inflammatory bowel disease (IBD) and 480 community controls. The crux of their findings was that obesity at time of diagnosis was approximately twice as common among Crohn's disease patients as among ulcerative colitis (UC) patients, and about three times as common among CD patients diagnosed in later life (ages 50 to 70 years) as among age-matched community controls.

One's first reaction upon reading these conclusions might be that they are counter-intuitive. Indeed, should CD patients not be skinnier rather fatter than normal by the time of diagnosis? Well, respond the authors, a group of them are in fact skinnier. At this point, they indicate that they found a "U-shaped" relationship between body mass index (BMI) and risk of CD, in which either very low or very high BMI seemed to confer a heightened risk of $\mathrm{CD}$ compared with UC or with controls. The investigators therefore speculate that there might be a unique subset of patients diagnosed with $\mathrm{CD}$ who have a distinct entity called "obesity-related enteropathy."

They are among the first to acknowledge a number of limitations to their conclusions. Their discussion includes

D. B. Sachar $(\bowtie)$

Mount Sinai School of Medicine, New York, NY, USA

e-mail: david.sachar@mountsinai.org thoughtful consideration of such issues as recall bias when weight and BMI data are based on recollections from many years earlier, small numbers of controls, differences in the catchment populations of the cases and controls, shifting time trends in BMI-distributions during the eras being studied, possible misclassifications between $\mathrm{CD}$ and UC, and the non-generalizability of findings among $\mathrm{CD}$ patients with onset after the age of 50 .

Two additional concerns in evaluating the strength of their conclusions are the lack of a prospective cohort to validate the hypotheses generated from the retrospective cohort, and the inability to identify with confidence those clinical or pathologic features that might serve to distinguish "obesity-related enteropathy" from the total pool of CD cases diagnosed at older ages.

Nonetheless, these authors propose a number of theoretical explanations for their findings that emphasize the intriguing links between obesity and inflammatory disease in general, and that call attention to the somewhat underappreciated role of adipose tissue in the pathogenesis of inflammation in particular. To quote J-F Colombel and his associates in France, adipose tissue is "an active and dynamic organ involved in the...regulation of immunity and inflammation" [2].

The importance of recognizing the participation of multiple cell types in immune and inflammatory processes cannot be overemphasized. For generations, we have thought of immunity and inflammation as being mediated by "professional" cells dedicated to these functions. Those discriminations are rapidly breaking down. Immunity and inflammation are turning out to be equal-opportunity processes.

The past 20 years of research in IBD have already elucidated multiple immunologic and inflammatory actions of epithelial cells [3, 4], endothelial cells [5], nerves [6], and 
other intestinal mesenchymal elements [7]. Studies of many other organ systems, including heart, lung, skin, and joints, have revealed similar critical roles for fibroblasts [8] and myocytes [9].

This widened appreciation of how different cell types mediate and potentiate inflammation brings us back specifically to the role of adipose tissue in IBD. To be sure, Colombel and Desreumaux and their colleagues have been alerting us for more than a decade to the potential importance of fat cells in intestinal inflammation [10]. More recent studies have pinpointed some of the specific mediators and receptors involved in this process [11].

Clinical epidemiology like that undertaken by Mendall et al. [1] will continue to prove valuable in unraveling these relationships. Meanwhile, we look to animal experimental models, genetics, cell biology, pathology, immunology, and, increasingly, to microbiology to shed further light on how the full complement of our cells, tissues, and organs contributes to the mysterious mechanisms of IBD.

\section{References}

1. Mendall MA, Genasekera AV, Biku JJ, Kumar DA. Is obesity a risk factor for Crohn's disease? Dig Dis Sci. 2011;56:INSERT.
2. Peyrin-Biroulet L, Chamaillard M, Gonzalez F, et al. Mesenteric fat in Crohn's disease: A pathogenic hallmark or an innocent bystander? Gut. 2007;56:577-583.

3. Salomon P, Pizzimenti A, Panja A, Reisman A, Mayer L. The expression and regulation of class II antigens in normal and inflammatory bowel disease peripheral blood monoctyes and intestinal epithelium. Autoimmunity. 1991;9:141-149.

4. Shkoda A, Ruiz PA, Kim SC, et al. Intestinal epithelial cell signaling and host-derived negative regulators under chronic inflammation. Inflamm Bowel Dis. 2006;12:S23.

5. Fiocchi C, Ina K, Danese S, Leite AZ, Vogel JD. Alterations of mesenchymal and endothelial cells in inflammatory bowel diseases. Adv Exp Med Biol. 2006;579:168-176.

6. Collins SM. Stress and the gastrointestinal tract. IV. Modulation of intestinal inflammation by stress: Basic mechanisms and clinical relevance. Am J Physiol. 2001;280:G315-G318.

7. Pinchuk IV, Mifflin RC, Saada JI, Powell DW. Intestinal mesenchymal cells. Curr Gastroenterol Rep. 2010;12:310-318.

8. Chapman HA. Epithelial-mesenchymal interactions in pulmonary fibrosis. Ann Rev Physiol. 2010. Epub ahead of print.

9. Trayhum P, Drevon CA, Eckel J. Secreted proteins from adipose tissue and skeletal muscle-adipokines, myokines, and adipose/ muscle cross-talk. Arch Physiol Biochem. 2010. Epub ahead of print.

10. Desreumaux P, Ernst O, Geboes K, et al. Inflammatory alterations in mesenteric adipose tissue in Crohn's disease. Gastroenterology. 1999; 117:73-81.

11. Konishi M, Nakamura H, Miwa H, Chambon P, Ornitz DM, Itoh N. Role of Fgf receptor 2c in adipocyte hypertrophy in mesenteric white adipose tissue. Mol Cell Endocrinol. 2008;287:13-19. 